\title{
How Not to Study a Disease: The Story of Alzheimer's by Karl Herrup, The MIT Press, 2021, 245 pp
}

Pre-press 31 January 2022

German philosopher George Wilhelm Friedrich Hegel once wrote that "the owl of Minerva spreads its wings only with the falling of the dusk." In other words, it is only in hindsight, after the events of an era have transpired, that we can truly comprehend their historical import.

In How Not to Study a Disease, neurobiologist Karl Herrup attempts a retrospective look at the myriad failures that have delivered the Alzheimer's field into its current predicament, and seeks to chart a wiser path forward. Herrup is chiefly concerned with examining how the amyloid cascade hypothesis became a totalizing force in the field ("if you're not studying amyloid, you're not studying Alzheimer's", he was told early in his career), and why fealty to this model has failed to produce effective treatments despite billions of dollars and the work of countless researchers.

His analysis implicates a broad swath of factors in the cul-de-sac of amyloid-based approaches. A political calculus that has, since Emil Kraepelin's decision to declare Alzheimer's a disease of plaques and tangles, consistently overruled common sense and inflated the likelihood of a cure; groupthink that led to the rejection or suppression of findings inconsistent with the amyloid cascade hypothesis; a quasi-religious faith in the power of genetics and pharmaceuticals to solve problems; industry incentives aligned with commercial profit rather than quality science; corrupt patronage systems of experts well-funded by industry and motivated by fame, reputation, and power; a compliant media that has failed to ask the hard questions when approaches clearly haven't worked. All of this is, from Herrup's birdseye view, decidedly not how you study a disease.
Of course, it is fair to question why Herrup's critique is being leveled now rather than in prior decades when aggressively challenging the field's guiding myths and orthodoxies carried far greater consequences. This deepens admiration for those voices that spoke up against the amyloid-centric theories, conceptual errors, and misguided values and priorities of the field when the professional costs for doing so were much more severe. Herrup is not so much leveling a new critique as synthesizing countervailing views previously expressed by past "heretics" who history has proven correct.

Nevertheless, Herrup argues that any path out of the current crisis will require a redefinition of Alzheimer's disease-one that is unfettered by the sclerotic amyloid-cascade hypothesis. He proposes a biological reconceptualization based on what he calls a "Neighborhood model". This "connectomics" approach begins by understanding the local interactions among different neural cell types (i.e., neighborhoods) and then working outwards in complexity to "cities" and "nations" to conceptualize how advancing loss of local functionality across vast interconnected networks could precipitate the emergence of dementia. Such a model is not novel, but may provide a better heuristic for conceptualizing a syndromal condition that is heterogeneous, age-related, and complex than the single-mechanism theories that have so paralyzed the Alzheimer's field.

Herrup also shares numerous recommendations to tweak funding mechanisms to steer resources to non-amyloid researchers, which-while certainly needed-is perhaps a tad self-serving. One major change he suggests is to defund the amyloid police at 
the NIA and allocate more money to NINDS where he believes he will find more neurologists sympathetic to his views. The problem is that many amyloidists are neurologists, and such a funding shift is not only politically unlikely but probably ineffective without the more profound changes in thinking about the syndrome that Herrup suggests. Besides, it is not clear Herrup has yet learned enough from neurologists who are sympathetic — at least to his direct assault against the domination of amyloid-but more aware than he is of clinical complexities.

One comes away from the book appreciative of Herrup's critique of the amyloid cabal, but also admittedly somewhat frustrated at his selective history, the limited questions he is asking, and the largely technocratic solutions he offers. Certainly, his proposed model is more multi-faceted than amyloid-cascade, but he still regards Alzheimer's as a "disease-to-be-cured" despite acknowledging its intimate relationship to aging ("Aging is an obligate part of Alzheimer's," as Herrup writes). It is fair to ask whether this reframing may ultimately launch us on a new quixotic quest for drug cocktails to forestall multiple brain aging pathways. Are such "anti-aging" approaches even feasible? If so, will they be clinically effective, affordable, scalable across populations?

Speaking of populations, there has been a fascinating trend in the last several decades of decreased dementia incidence in the US, Canada, the UK, France, Sweden, and the Netherlands [1]. These shifts appear to be linked with public health and policy measures favorable to brain health implemented in the 20th-century: increased total years of higher education; better treatment of vascular disease risk via expanded healthcare systems; reduced smoking rates thanks to public health efforts; lower lead exposure due to the de-leading of gasoline; reductions in air pollution, etc. [2]. Researchers linking biobank data (i.e., neuropathology) with social vulnerability indices have also found that the material conditions in real-world "neighborhoods" impact brain health down to the zip code level [3].

Herrup unfortunately omits these compelling findings, but his book would have benefited from a greater focus on epidemiology, public health, and public policy-ironically, on what has been recently learned about brain health at the level of literal neighborhoods, cities, and nations. Broad-based thinking, rather than biological reductionism, is what history seems to be teaching us is imperative to "how to study the disease" in the 21 st century, especially as the US deals with a rising chronic disease epidemic, a renewed lead crisis (this time in drinking water), massive numbers of un- and under-insured citizens, downward trends in higher education rates, and record income/wealth inequality. As he closes his book, Herrup ultimately argues that "we must do something right away" to reverse course on Alzheimer's; such findings from beyond the limited scope of neurobiology would seem to have helped inform a timely and actionable road map.

Daniel R. George, PhD, MSc Associate Professor

Penn State College of Medicine dgeorge1@pennstatehealth.psu.edu

Peter J. Whitehouse, MD, PhD

Professor

Case Western Reserve University pjw3@case.edu

\section{REFERENCES}

[1] Wolters FJ, Chibnik LB, Waziry R, Anderson R, Berr C, Beiser A, Bis JC, Blacker D, Bos D, Brayne C, Dartigues JF, Darweesh SKL, Davis-Plourde KL, de Wolf F, Debette S, Dufouil C, Fornage M, Goudsmit J, Grasset L, Gudnason V, Hadjichrysanthou C, Helmer C, Ikram MA, Ikram MK, Joas E, Kern S, Kuller LH, Launer L, Lopez OL, Matthews FE, McRae-McKee K, Meirelles O, Mosley TH Jr, Pase MP, Psaty BM, Satizabal CL, Seshadri S, Skoog I, Stephan BCM, Wetterberg H, Wong MM, Zettergren A, Hofman A (2020) Twenty-seven-year time trends in dementia incidence in Europe and the United States: The Alzheimer Cohorts Consortium. Neurology 95, e519-e531.

[2] George DR, Whitehouse PJ (2021) American Dementia: Brain Health in an Unhealthy Society. Johns Hopkins University Press, Baltimore.

[3] Powell WR, Buckingham WR, Larson JL, Vilen L, Yu M, Salamat MS, Bendlin BB, Rissman RA, Kind AJH (2020) Association of neighborhood-level disadvantage with Alzheimer disease neuropathology. JAMA Network Open 3, e207559. 